\title{
Measuring income inequalities beyond the Gini coefficient
}

\author{
Mikuláš Luptáčik ${ }^{1,2} \cdot$ Eduard Nežinský $^{2}$
}

Published online: 22 November 2019

(c) The Author(s) 2019

\begin{abstract}
Growing interest in the analysis of interrelationships between income distribution and economic growth has recently stimulated new theoretical and empirical research. Measures such as the head-count ratio for the poverty index or the widely used Gini coefficient are aggregated indicators describing the general extent of inequality without deeper insights into income distribution among households. To derive an indicator accounting for income distribution among income groups, we propose a new approach based on an output oriented DEA model where the input value is unitized to 1 for each country and weights restrictions imposed so as to favour a higher income share in the lower quantiles. We demonstrate the merits of this approach on the quintile income breakdown data of 29 European countries. Prioritizing lower income groups' welfare, countries such as Slovenia and Slovakia can be equally favoured by the new proposed indicator while being assessed differently by the Gini index. An intertemporal analysis reveals a slight deterioration of income distribution in the majority of 29 European countries over the period of 2007-2016 in a Rawlsian sense.
\end{abstract}

Keywords Income distribution · Rawlsian utility · Data envelopment analysis · Weights restriction $\cdot$ Malmquist index

\section{Introduction}

Income distribution and its relation to economic activity and social welfare have become one of the main interests of numerous theoretical and empirical studies over the last three decades. Some of these papers are based on social welfare functions and assess the trade-off between efficiency and equity (Nicola 2013).

Mikuláš Luptáčik

Mikulas.Luptacik@wu.ac.at

Eduard Nežinský

eduard.nezinsky@euba.sk

1 Vienna University of Economics and Business, Welthandelsplatz 1, 1020 Vienna, Austria

2 University of Economics in Bratislava, Dolnozemská cesta 1, 85106 Bratislava, Slovakia 
An empirical analysis of welfare and economic performance involves accounting for multiple socio-economic characteristics. Welfare depends on both the size and distribution of national income. With its capacity to account for multiple inputs and outputs, data envelopment analysis (DEA) has proved to be an appropriate tool in this domain. Prasada Rao and Coelli $(1998,2002)$ were the first to embed inequality indicator in the measuring of economic performance. Lábaj et al. (2014) later derived a measure of social welfare which simultaneously assesses economic, ecological, and social dimensions. Using DEA the overall change in productivity described by the Malmquist index can be decomposed to expose catch-up and frontier-shift effects (see e.g. Färe et al. 1994; Cooper et al. 2007).

As pointed out by Nicola (2013, p. vi), many indicators of welfare other than income, e.g. education, good health, or happiness show a positive correlation between per capita income and a satisfaction score. A new indicator for measuring economic performance beyond GDP which includes inequality was developed by Jones and Klenow (2016).

Statistically based studies that measure income distribution indicate a widening gap between the income of rich and poor individuals during the last three decades (e.g. Atkinson 2015; Atkinson et al. 2011). Following Feldstein (2005), "the emphasis should be on eliminating poverty and not on the overall distribution of income or the general extent of inequality. Like most economists, I accept the Pareto principle that an economy is better off if someone gains and no one loses. This is true even if the gainer has above-average income, causing a Gini coefficient measure of income distribution to shift to greater inequality", (p. 12). Atkinson (2015) supports this view: "I share his concern with what is happening at the bottom of the income scale" (p. 23).

The simplest way to extract the poverty indicator from income distribution is to define an income value, $y_{\min }$, and to declare as poor those people with an income that does not exceed it. However, this so-called head-count ratio does not take into account income distribution among individuals in this group. For the same Gini coefficient, the income share of the poorest group in relation to total income can be different. A deeper insight in the structure of the inequality measure is needed.

The remainder of the paper is organized as follows. The next section is devoted to the measurement of income distribution based on DEA methodology. As the evaluation of income distribution encompasses both descriptive and prescriptive issues (Sen 2000), some preferences need to be included in the prospective method. In the spirit of Rawls and following Feldstein (2005) we introduce decreasing weighting for income quantile shares, with the highest weight for the poorest group. A assurance region DEA model is employed to implement these weight restrictions. A method of assessing of productivity change over time using the Malmquist index is presented afterwards. In Sect. 3 empirical results are presented to demonstrate how the proposed measure performs compared to the Gini index, providing deeper insight into individual distributions in 29 European countries. The intertemporal analysis spans the period of 2007-2016. Section 4 concludes and outlines further research. 


\section{Measurement of inequalities}

Over the years, a multitude of indices haves been developed to facilitate the designing and evaluating of policies with respect to social development. Most of them aim to capture aspects beyond GDP utilizing a range of indicators, famously articulated in Stiglitz et al. (2009). Leaving aside environmental issues, the most discussed aspect of well-being is social justice, particularly the distribution of wealth. There are a number of indicators capturing the distribution of wealth or income on an aggregate level, including the Gini or Theil indices as a class of statistically based indicators. These indices are closely linked to social welfare functions. Quantities characterizing health or education are closely correlated with income. This is why income distribution analyses dominate the domain of the social aspect of well-being research.

Measures like the head-count ratio for the poverty index or the widely used Gini coefficient do not provide deeper insights into income distribution among the different types of households. It is important to know not only the surface generated by the Lorenz curve for the estimation of the Gini coefficient but also the curvature of this curve. Adopting the definition of justice as representing "...the basic structure of society" (Rawls 1971) and Feldstein's (2005) focus on eliminating poverty, we would value overall welfare with respect to the lowest income. We deviate from the strict max-min principle, maintaining however the spirit of lower incomes'-greater contribution to total welfare. Since detailed data on income brackets are hardly available for a study across European countries, we make use of income distribution data where income shares per population quantiles are accessible. The more income is received by the poorest, the higher "Rawlsian" social welfare would be generated.

\subsection{Measurement of inequalities with a weight restriction in DEA}

In order to provide deeper insights into income distribution among the different income groups, e.g. quantiles of households by level of income) and, thus, to reveal the potential for reducing income inequalities we propose a modified DEA model. DEA was originally developed for measuring efficiency and evaluating the performance of many different kinds of entities engaged in many different activities (Charnes et al. 1978). Applications of DEA include evaluations of the performance of cities, regions and countries with different kinds of inputs and outputs which can be expressed in different (monetary, physical) units. DEA does not require any assumption about the functional form of the transformation function and provides a single measure of efficiency without needing to assign prespecified weights to multiple inputs and outputs. It measures the efficiency of a decision making unit (DMU) relative to all other DMUs with the simple restriction that all other DMUs lie on or below the efficiency frontier. For each inefficient DMU DEA identifies the sources and level of inefficiency for each of the inputs and outputs.

The basic DEA model can easily be extended according to the research question or the field of applications (an extensive account is given, for example, in Cooper et al. 
2007). One very useful modification is related to the situation where differing importance or priorities with respect to particular inputs or outputs are defined and should be taken into account. Accepting Rawls criterion and Feldstein's argument for increasing social welfare - an increase in poorer household's income generates higher social welfare than an increase in richer households' income-we propose the idea of an "assurance region" DEA model.

Let us illustrate this idea using a very simple example with two outputs (the shares of income owned by two types of households, poor and rich, whose values add up to one) and three countries (DMUs). The data are given in the following table.

\begin{tabular}{llll}
\hline Country & Output 1 & Output 2 & Input \\
\hline A & 0.3 & 0.7 & 1 \\
B & 0.7 & 0.3 & 1 \\
C & 0.5 & 0.5 & 1 \\
\hline
\end{tabular}

In the output oriented model aiming at maximizing the aggregated sum of the outputs, the linear programming constraints associated with countries $\mathrm{A}, \mathrm{B}$, and $\mathrm{C}$ have the following inequalities in common along with the non-negativity constraint for all variables:

$$
\begin{aligned}
& v-0.3 u_{1}-0.7 u_{2} \geq 0 \\
& v-0.7 u_{1}-0.3 u_{2} \geq 0 \\
& v-0.5 u_{1}-0.5 u_{2} \geq 0,
\end{aligned}
$$

where $v$ denotes the input multiplier and $u_{1}, u_{2}$ label output multipliers.

This is a very simple output oriented model where all three countries are efficient (none of the countries is dominated by another one or a combination of the other countries). In order to demonstrate the role of weight for identifying the Charnes-Cooper-Rhodes (CCR) efficiency of DMUs, we will graphically show the efficiency frontier for this example in the weight variables (multiplier) space. Because there are only two outputs and one unitized input, we can plot a two-dimensional graph.

Dividing the inequalities constraints by $v>0$, the following expressions are obtained:

$$
\begin{aligned}
& 0.3 \frac{u_{1}}{v}+0.7 \frac{u_{2}}{v} \leq 1 \\
& 0.7 \frac{u_{1}}{v}+0.3 \frac{u_{2}}{v} \leq 1 \\
& 0.5 \frac{u_{1}}{v}+0.5 \frac{u_{2}}{v} \leq 1
\end{aligned}
$$


Taking $u_{1} / v$ and $u_{2} / v$ as axes, the area $\mathrm{P} \equiv \mathrm{OP}_{4} \mathrm{P}_{0} \mathrm{P}_{3}$ in Fig. 1 shows the set of feasible solutions for the above constraints. The line segments $\mathrm{P}_{3} \mathrm{P}_{0}$ and $\mathrm{P}_{0} \mathrm{P}_{4}$, where $\mathrm{P}_{0}$ is intersection of the three lines describe the efficiency frontier.

All three countries $\mathrm{A}, \mathrm{B}$, and $\mathrm{C}$ are efficient. Any $\left(u_{1}, u_{2}\right)$ on the line segment $\mathrm{P}_{3} \mathrm{P}_{0}$ expresses the optimal weights for $\mathrm{A}$, segment $\mathrm{P}_{0} \mathrm{P}_{4}$ represents optimal combinations of weights for $\mathrm{B}$, and $\mathrm{P}_{2} \mathrm{P}_{0}$ for country $\mathrm{C}$. It is easy to see that the optimal weights for an efficient DMU need not to be unique.

In the spirit of Rawls we now postulate a higher weight for the income of the poorer households. For this purpose we introduce condition $u_{2} \leq 0.7 u_{1}$ (ensuring that $u_{1}>u_{2}$ and allowing for a graphically discernible representation). We thus require that the weight for the income of a poor household is at least 1.43 times higher than the weight for a rich household. In the empirical part of the paper, we will alter the lower bound for the weights ratio and analyse the effect of the change for the discrimination power of our measure.

To analyse the influence of the assurance region method on the efficiency frontier and to illustrate our inequality measure, we add the weight constraint $u_{2} \leq 0.7 u_{1}$ in the $(v, \mathbf{u})$ space in Fig. 1. Dividing the weight restriction inequality by $v>0$ and rewriting we obtain

$$
\frac{u_{2}}{v}-0.7 \frac{u_{1}}{v} \leq 0
$$

The segment line OR corresponding to the equation, obtained by rewriting the above inequality intersects the segment line $\mathrm{P}_{0} \mathrm{P}_{4}$ at point $\mathrm{R}$ in Fig. 2. Consequently, the feasible region in the $(v, \mathbf{u})$ space is now represented by the triangle $\mathrm{ORP}_{4}$, and

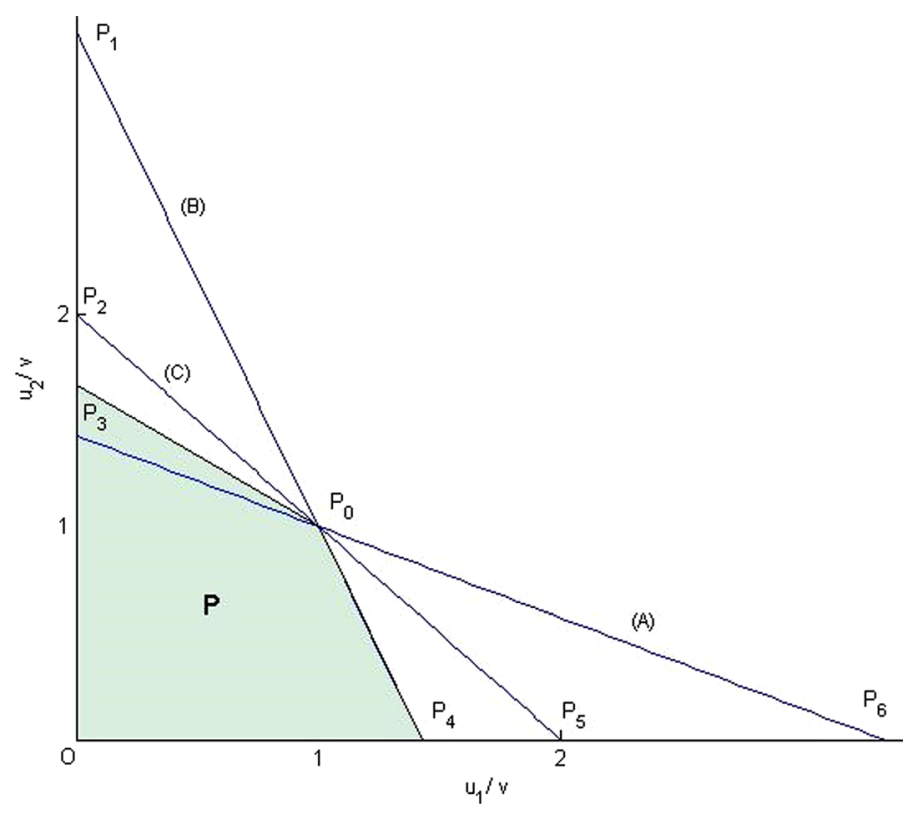

Fig. 1 Feasible region $\mathrm{P}$ 


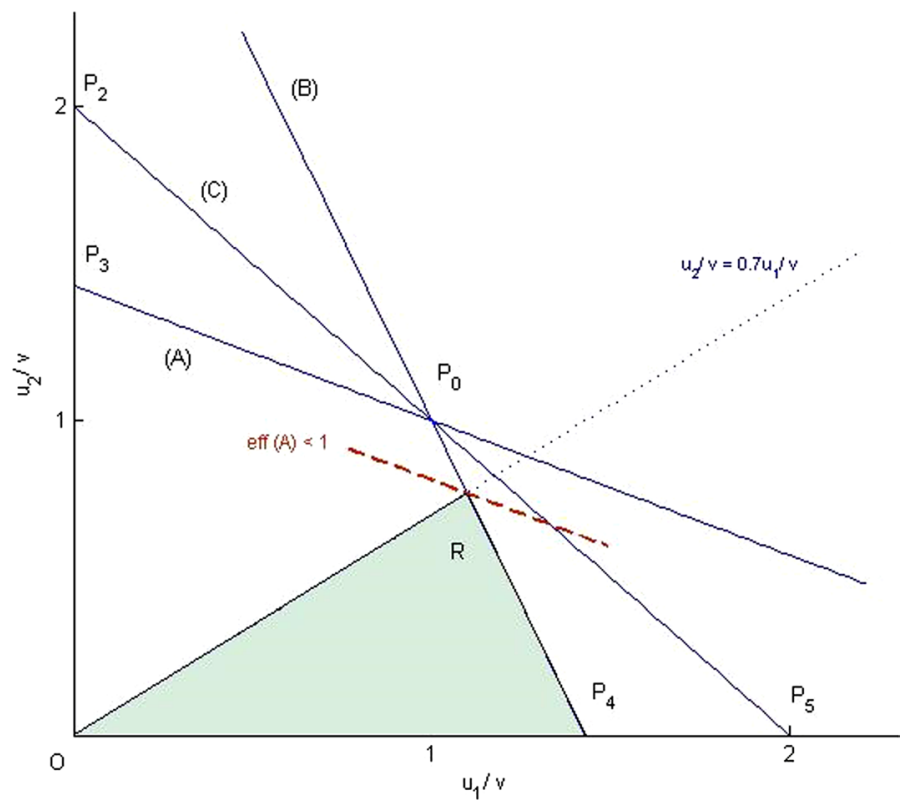

Fig. 2 Assurance region

the line segments $\mathrm{P}_{3} \mathrm{P}_{0}$ and $\mathrm{P}_{0} \mathrm{R}$ are shut out from the efficiency frontier by the assurance region constraint. The efficiency frontier is now described by the line segment $\mathrm{RP}_{4}$ and the only efficient unit remains country $\mathrm{B}$.

Taking a look at the data confirms that, this result is in accordance with economic reasoning. The income's share of household 1 (output 1 with higher weight) in country B is higher than in the other two countries.

To see the impact of the weight restriction on the efficiency scores of the DMUs $\mathrm{A}$ and $\mathrm{C}$ and to provide an interpretation of our DEA inequality measure we move the line segments $\mathrm{P}_{3} \mathrm{P}_{\mathrm{o}}$ (which corresponds to country A) parallel to touch the efficiency frontier at point $\mathrm{R}$ with coordinates $u_{1} / \nu=1.1$ and $u_{2} / v=0.77$. The efficiency score of country A is then

$$
0.3 \frac{u_{1}}{v}+0.7 \frac{u_{2}}{v}=0.869
$$

Thus the efficiency of DMU A drops to 0.869. Similarly, if we move the line segment $\mathrm{P}_{2} \mathrm{P}_{5}$ parallel to point $\mathrm{R}$, the efficiency of DMU $\mathrm{C}$ is reduced to 0.934 . The impact of the weight constraint for country $\mathrm{C}$ is smaller than for $\mathrm{A}$, which is not surprising looking at the data in our example.

Summarizing, the inequality indicator obtained by an assurance region modification of the CCR model is smaller or equal to one and describes the amount of outputs that must be redistributed in order to be projected on the frontier. The greater the redistribution that is needed, the lower the value of the resulting score. Unit value of the score indicates that the DMU lies on the efficiency frontier defining the benchmark and that no redistribution is needed. 


\subsection{Assurance region programs}

Extending the considerations from the previous section for more than two outputs and with more countries under assessment, the output oriented radial model, in the notation of Cooper et al. (2007) takes the following form.

$$
\begin{gathered}
(R 1) \quad \min _{\mathbf{u}, \mathbf{v}} \quad \mathbf{v}^{\mathrm{T}} \mathbf{x}_{0} \\
\text { s.t. } \quad \mathbf{u}^{\mathrm{T}} \mathbf{y}_{0}=1 \\
-\mathbf{v}^{\mathrm{T}} \mathbf{X}+\mathbf{u}^{\mathrm{T}} \mathbf{Y} \leq \mathbf{0} \\
\mathbf{u}^{\mathrm{T}} \mathbf{Q} \leq \mathbf{0} \\
\mathbf{u} \geq \mathbf{0}, \mathbf{v} \geq \mathbf{0},
\end{gathered}
$$

where $\mathbf{X}$ and $\mathbf{Y}$ are input and output data matrices respectively (with $n$ DMUs, $m$ inputs and s outputs), $\mathbf{u}$ and $\mathbf{v}$ are multipliers, and while $\mathbf{Q}$ is a matrix of bounds for the output weights.

From the point of view of decision makers benchmarks providing theoretical support for redistributive politics are of the great interest. The proposed model projects observed data onto the efficiency frontier utilizing optimal solutions from the dual envelopment program

$$
\begin{gathered}
\max _{\varphi, \lambda, \boldsymbol{\tau}} \varphi \\
\text { s.t. } \quad \mathbf{x}_{0} \geq \mathbf{X} \boldsymbol{\lambda} \\
\varphi \mathbf{y}_{0} \leq \mathbf{Y} \boldsymbol{\lambda}+\mathbf{Q} \boldsymbol{\tau} \\
\boldsymbol{\lambda} \geq \mathbf{0}, \boldsymbol{\tau} \geq \mathbf{0},
\end{gathered}
$$

where $\tau$ are dual variables associated with weight restrictions in (4). The output projections of interest are then calculated by means of the optimal values $\lambda^{*}$ as $\hat{\mathbf{y}}_{0}=\mathbf{Y} \lambda^{*}$.

The $R I$ index derived and illustrated in Sect. 2.1 assesses the level of inequality in a given period of time as the level of redistributions among households needed in order to be projected on the frontier.

This approach can be further utilized to analyse intertemporal changes in individual countries and/or the shift of the frontier. For this purpose the Malmquist productivity index (10) is employed. Based on the pioneering work of Caves et al. (1982), Färe and Grosskopf (1992) defined the index in terms of distance functions triggering a mass of studies employing the approach in a variety of applications up until now. 


$$
M=C \times F=\frac{d^{2}\left(\mathbf{x}_{0}, \mathbf{y}_{0}\right)^{2}}{d^{1}\left(\mathbf{x}_{0}, \mathbf{y}_{0}\right)^{1}}\left[\frac{d^{1}\left(\mathbf{x}_{0}, \mathbf{y}_{0}\right)^{1}}{d^{2}\left(\mathbf{x}_{0}, \mathbf{y}_{0}\right)^{1}} \times \frac{d^{1}\left(\mathbf{x}_{0}, \mathbf{y}_{0}\right)^{2}}{d^{2}\left(\mathbf{x}_{0}, \mathbf{y}_{0}\right)^{2}}\right]^{1 / 2}
$$

Expression (10) shows that the overall change in performance, in the case of the fixed input driven effectively by changes in the outputs, can be decomposed into two factors- the catch-up effect $(\mathrm{C})$ and the frontier-shift effect $(\mathrm{F})$.

A DMU $U_{0}$ represented by the activities $\left(\mathbf{x}_{0}, \mathbf{y}_{0}\right)^{t},(t=1,2)$ is assessed in two time periods with respect to two technology frontiers in periods 1 and 2 by distance functions $d^{S},(S=1,2)$. Thus we compute the terms involved in (10) by solving linear programs of two types. Within scores are obtained by optimization

$$
\begin{aligned}
& d^{S}\left(\mathbf{x}_{0}, \mathbf{y}_{0}\right)^{S}=\max _{\varphi, \lambda} \varphi \\
& \text { s.t. } \quad \mathbf{x}_{0}^{S} \geq \mathbf{X}^{S} \boldsymbol{\lambda} \\
& \varphi \mathbf{y}_{0}^{S} \leq \mathbf{Y}^{S} \boldsymbol{\lambda}+\mathbf{Q} \tau \\
& \lambda \geq 0, \boldsymbol{\tau} \geq 0,
\end{aligned}
$$

where $\mathbf{X}^{S}=\left(\mathbf{x}_{1}^{S}, \ldots, \mathbf{x}_{m}^{S}\right)$ and $\mathbf{Y}^{S}=\left(\mathbf{y}_{1}^{S}, \ldots, \mathbf{y}_{s}^{S}\right)$ are input and output data matrices respectively for the period $S$.

Intertemporal scores come from the program in the form

$$
\begin{aligned}
& d^{S}\left(\mathbf{x}_{0}, \mathbf{y}_{0}\right)^{t}=\max _{\varphi, \lambda} \varphi \\
& \text { s.t. } \quad \mathbf{x}_{0}^{t} \geq \mathbf{X}^{S} \lambda \\
& \varphi \mathbf{y}_{0}^{t} \leq \mathbf{Y}^{S} \lambda+\mathbf{Q} \tau \\
& \lambda \geq 0, \quad \boldsymbol{\tau} \geq 0,
\end{aligned}
$$

This program is solved for the pairs $(\mathrm{t}, \mathrm{S})=(1,2)$ and $(2,1)$. We thus employ the "exclusive" scheme (Cooper et al. 2007, p. 333) allowing the value of $d$ in (12) to take on values lower than the unit in the sense of super-efficiency (Thomson et al. 1986).

\section{Empirical results}

For an empirical demonstration of the $R I$ index performance we consider 29 European countries acting as DMUs. The data were sourced from Eurostat and comprise the Gini index and income shares of disposable income of five quintile population groups based on the EU-SILC survey, the latter entering our model as five outputs. For the intertemporal analysis we collected data from 2 years-2007 and 2016. Concentrating on outputs we fix input to unit value. The input data matrix thus collapses to a unit vector rendering the model robust to the returns to scale assumption. To increase the discriminating power of the model, we can set the Rawlsian weights constraints in a stricter way, letting the ratio of the successive multipliers be bounded by a specified number $l$. Matrix $\mathbf{Q}$ from (4) will then take the form 


$$
\mathbf{Q}=\left(\begin{array}{cccc}
l_{1,2} & 0 & 0 & 0 \\
-1 & l_{2,3} & 0 & 0 \\
0 & -1 & l_{3,4} & 0 \\
0 & 0 & -1 & l_{4,5} \\
0 & 0 & 0 & -1
\end{array}\right),
$$

where $0<l_{i, j}<1, i=1,2,3,4 ; j=2,34,5$. In this way a sequentially constrained weights are embodied in the DEA model. We exemplify our approach by choosing the values for $l_{i, j}$ from the matrix $\mathbf{Q}$ equal to 0.9 . This implies the following decreasing sequence of weights

$$
u_{1}>u_{2}>u_{3}>u_{4}>u_{5} \text {. }
$$

Solving the assurance model for each DMU we calculate the RI indicator for 2016 as well as optimal values for the weights and dual variables. In Table 1 the data and values of the RI index are displayed along with the corresponding value of the Gini index. The complete results for all countries can be viewed in Table 6 ("Appen$\operatorname{dix}$ A").

The model determines four efficient DMUs with the unit score-the Czech Republic, Slovenia, Slovakia, and Norway, which are the countries with the lowest Gini coefficients. Noticeably, the Czech Republic gained its RI-efficiency from the massive income share of the first quintile income group (the poorest $20 \%$ ). Slovenia and Slovakia (both relative efficient according to the RI) differ slightly in their Gini index at -24.4 and 24.3 respectively, with Slovenia offsetting an advantage in Q1 (9.5 vs. 9.3$)$ by a poorer value in Q2 (14.9 vs. 15.2). Germany and Ireland with the same value of Gini (29.5) are indistinguishable with the chosen ratio of weights. When compared to Hungary, Ireland's share in Q2 and Q3 is lower (while Q1 are equal) which results in a lower RI score for Ireland.

A comparison of the results for the Czech Republic and Denmark for the year 2007 (see "Appendix A", Table 7) reveals the difference between our RI indicator (see column d11) and the Gini coefficient (see column G07). The lower Gini coefficient for

Table 1 Data, RI scores, and the Gini index for selected countries (2016, l=0.9). Source: Authors'

\begin{tabular}{|c|c|c|c|c|c|c|c|c|}
\hline & & Q1 & Q2 & Q3 & Q4 & Q5 & RI & Gini \\
\hline 2 & Bulgaria & 5.6 & 11.4 & 16.2 & 22.6 & 44.2 & 0.966 & 38.3 \\
\hline 3 & Czech Republic & 10.1 & 14.6 & 17.9 & 22.0 & 35.4 & 1 & 25.1 \\
\hline 4 & Denmark & 9.0 & 14.2 & 17.9 & 22.2 & 36.7 & 3 & 27.7 \\
\hline 5 & Germany & 8.2 & 13.5 & 17.7 & 22.8 & 37.8 & 0.987 & 29.5 \\
\hline 7 & Irelan & 8.6 & 13.1 & 17.6 & 22.9 & 37.8 & 0.988 & 29.5 \\
\hline 14 & Lithuania & 6.1 & 11.4 & 16.2 & 22.9 & 43.4 & 0.968 & 37.0 \\
\hline 16 & Hungary & 8.6 & 13.9 & 17.8 & 22.9 & 36.8 & 0.991 & 28.2 \\
\hline 23 & Slov & 9.5 & 14.9 & 18.7 & 22.9 & 34.0 & 1 & 24.4 \\
\hline 24 & Slov & 9.3 & 15.2 & 18.8 & 23.0 & 33.7 & 1 & 24.3 \\
\hline 25 & Finland & 9.9 & 14.3 & 18.0 & 22.4 & 35.4 & 0.998 & 25.4 \\
\hline 28 & Norway & 9.4 & 15.1 & 18.5 & 22.4 & 34.6 & 0.999 & 25.0 \\
\hline
\end{tabular}
calculations 
Denmark (25.2) indicates a lower general extent of inequality than in the Czech Republic (where the Gini coefficient is 25.3). However the RI index for the Czech Republic is higher than for Denmark, reflecting the higher income share of the first quantile in the Czech Republic (10.1) — with the highest weight—compared with the income share for this group in Denmark (9.2). See "Appendix A", Table 5 for further details.

Having demonstrated the sensitivity of the proposed measure, we derive results which are potentially useful for policy making. The projections for outputs suggest a desirable income share adjustment in individual quintile groups needed to perform at the best practice level. In this way, the potential identified for reducing income inequality provides further important merit and difference of the RI indicator compared with the Gini coefficient. An example of selected countries is given in Table 2. Adjustments in the table are computed as differences between the projection and the data, so positive values indicate the need to increase the share of a particular income group.

Naturally, in the Rawlsian sense the most massive redistribution would be needed in the "richest" quantiles as indicated by the negative values of the suggested adjustments. Clearly, for efficient DMUs like the Czech Republic, no changes are needed and the adjustments are zero. Since projections add up to unity, adjustments add up to zero (proof in "Appendix B"). The extreme value for Bulgaria suggests a need for an extensive redistribution from Q5 $(-10.5)$. The complete results are given in Table 6 ("Appendix A").

The intertemporal analysis was conducted by calculating the $d$-terms described in Sect. 2.2, labeled $\mathrm{d} 11$ and $\mathrm{d} 22$ (within the scores for 2007 and 2016) along with $\mathrm{d} 21$ and d12 (intertemporal scores). Then the catch-up (C) and frontier-shift (F) effects as well as the overall Malmquist productivity index (M) were computed. A selection of countries is given in Table 3, the complete results can be seen in Table 7 ("Appendix A").

In Table 3, within the score for the period 2 (d22) is identical to the RI index (efficiency score) for 2016 analysed above. The new insights provided by the RI index and its discriminating capacity in comparison to the Gini coefficient can be seen in

Table 2 Income share adjustment (2016, $l=0.9)$. Source: Authors' calculations

\begin{tabular}{|c|c|c|c|c|c|c|c|}
\hline & & \multirow[t]{2}{*}{ RI } & \multicolumn{5}{|c|}{ Adjustment } \\
\hline & & & Q1 & $\mathrm{Q} 2$ & Q3 & $\mathrm{Q} 4$ & Q5 \\
\hline 2 & Bulgaria & 0.966 & 3.7 & 3.8 & 2.6 & 0.4 & -10.5 \\
\hline 3 & Czech Republic & 1 & & & & & \\
\hline 4 & Denmark & 0.993 & 0.3 & 1.0 & 0.9 & 0.8 & -3.0 \\
\hline 5 & Germany & 0.987 & 1.1 & 1.7 & 1.1 & 0.2 & -4.1 \\
\hline 7 & Ireland & 0.988 & 0.7 & 2.1 & 1.2 & 0.1 & -4.1 \\
\hline 14 & Lithuania & 0.968 & 3.2 & 3.8 & 2.6 & 0.1 & -9.7 \\
\hline 16 & Hungary & 0.991 & 0.7 & 1.3 & 1.0 & 0.1 & -3.1 \\
\hline 23 & Slovenia & 1 & & & & & \\
\hline 24 & Slovakia & 1 & & & & & \\
\hline 25 & Finland & 0.998 & 0.0 & 0.4 & 0.1 & -0.2 & -0.4 \\
\hline 28 & Norway & 0.999 & 0.0 & 0.0 & 0.2 & 0.5 & -0.7 \\
\hline
\end{tabular}


Table 3 The Malmquist index, its components and the change in the Gini index for selected countries $(l=0.9)$. Source: Authors' calculations

\begin{tabular}{|c|c|c|c|c|c|c|c|c|c|}
\hline & & $\mathrm{d} 11$ & $\mathrm{~d} 22$ & $\mathrm{~d} 21$ & $\mathrm{~d} 12$ & $\mathrm{C}$ & $\mathrm{F}$ & $\mathrm{M}$ & $\mathrm{G} 2 / \mathrm{G}$ \\
\hline 2 & Bulgaria & 0.970 & 0.966 & 0.973 & 0.963 & 0.996 & 0.997 & 0.993 & 1.085 \\
\hline 3 & Czech Republic & 0.999 & 1.000 & 1.000 & 1.000 & 1.000 & 1.000 & 1.000 & 0.992 \\
\hline 4 & Denmark & 0.995 & 0.993 & 0.998 & 0.990 & 0.998 & 0.997 & 0.995 & 1.099 \\
\hline 5 & Germany & 0.983 & 0.987 & 0.985 & 0.985 & 1.005 & 0.997 & 1.002 & 0.970 \\
\hline 7 & Ireland & 0.980 & 0.988 & 0.983 & 0.985 & 1.008 & 0.997 & 1.005 & 0.942 \\
\hline 14 & Lithuania & 0.974 & 0.968 & 0.976 & 0.966 & 0.995 & 0.997 & 0.992 & 1.095 \\
\hline 16 & Hungary & 0.995 & 0.991 & 0.998 & 0.988 & 0.996 & 0.997 & 0.993 & 1.102 \\
\hline 23 & Slovenia & 1.000 & 1.000 & 1.025 & 0.997 & 1.000 & 0.986 & 0.986 & 1.052 \\
\hline 24 & Slovakia & 0.998 & 1.000 & 1.009 & 0.997 & 1.002 & 0.993 & 0.995 & 0.992 \\
\hline 25 & Finland & 0.994 & 0.998 & 0.997 & 0.995 & 1.005 & 0.997 & 1.001 & 0.969 \\
\hline \multirow[t]{2}{*}{28} & Norway & 1.000 & 0.999 & 1.018 & 0.996 & 0.999 & 0.990 & 0.989 & 1.055 \\
\hline & Average (total) & & & & & 1.001 & 0.996 & 0.997 & \\
\hline
\end{tabular}

the example of Slovakia versus the Czech Republic. Slovakia's Gini index changed from 24.5 to 24.3 between 2007 and 2016, i.e. to lower inequality. However, the RI approach indicates a deterioration in the Rawlsian performance by the $\mathrm{M}$ value of $0.995<1$, i.e. in the opposite direction. The Gini coefficient is an absolute measure of inequality while the DEA based RI index is a relative one. Inequality in Slovakia did decrease but the improvement was lower than the improvement in the reference country of the Czech Republic. The data for the Czech Republic and Slovakia reveals that, the share of the first quantile with the highest weight was at the same level in 2007 and 2016 in the Czech Republic while in Slovakia it decreased from 10.0 to 9.3. The Gini coefficient dropped in both countries though the RI Malmquist index for Slovakia decreased too. This exemplifies the difference between the Gini and RI measures. On average, the productivity index $M$ which is slightly below 1 (see Table 3 ) suggests less egalitarian distributions across Europe in 2016 compared to 2007 The efficiency frontier-shift effect defined by the most efficient countries reveals a deteriorating in the best practice itself. Most individual catch-up is observed in Portugal, Romania, Poland, and Ireland contributing heavily to the general improvement $(\mathrm{M}>1)$. Less impressive progress has been made by Germany, Latvia, Netherlands, the United Kingdom, and Switzerland (see Table 7, "Appendix A").

In order to increase the discrimination power of our measure we sharpened the differences between the weights by reducing the value of $l_{i, j}$ of to 0.7 (see Table 4 and for more details Table 8, "Appendix A").

The results show the decreasing values of the inequality indicators RI and increasing discrimination in the country's performance. Looking at the DEA results with respect to the peer group shows the improving performance of the Czech Republic (the country with the highest income share for the first quantile) due to the increasing weight of the first group. The reference set for 2016 for all countries (excluding Norway) consists the Czech Republic only. This illustrates the dependence of results on the change of the coefficient $l$, describing the decreasing sequence of weights. 
Table 4 The Malmquist index, its components and Gini change for selected countries $(l=0.7)$. Source: Authors' calculations

\begin{tabular}{|c|c|c|c|c|c|c|c|c|c|}
\hline & & d11 & $\mathrm{d} 22$ & $\mathrm{~d} 21$ & $\mathrm{~d} 12$ & $\mathrm{C}$ & $\mathrm{F}$ & M & G21 \\
\hline 2 & Bulgaria & 0.895 & 0.884 & 0.905 & 0.874 & 0.988 & 0.989 & 0.977 & 1.085 \\
\hline 3 & Czech Republic & 0.999 & 1.000 & 1.000 & 0.999 & 1.001 & 0.999 & 1.000 & 0.992 \\
\hline 4 & Denmark & 0.983 & 0.978 & 0.994 & 0.967 & 0.995 & 0.989 & 0.984 & 1.099 \\
\hline 5 & Germany & 0.940 & 0.958 & 0.951 & 0.947 & 1.018 & 0.989 & 1.007 & 0.970 \\
\hline 7 & Ireland & 0.934 & 0.960 & 0.944 & 0.949 & 1.028 & 0.989 & 1.017 & 0.942 \\
\hline 14 & Lithuania & 0.910 & 0.893 & 0.920 & 0.883 & 0.981 & 0.989 & 0.970 & 1.095 \\
\hline 16 & Hungary & 0.982 & 0.969 & 0.993 & 0.958 & 0.987 & 0.989 & 0.976 & 1.102 \\
\hline 23 & Slovenia & 1.000 & 1.000 & 1.024 & 0.988 & 1.000 & 0.982 & 0.982 & 1.052 \\
\hline 24 & Slovakia & 0.993 & 1.000 & 1.008 & 0.989 & 1.008 & 0.986 & 0.994 & 0.992 \\
\hline 25 & Finland & 0.980 & 0.995 & 0.991 & 0.984 & 1.016 & 0.989 & 1.004 & 0.969 \\
\hline \multirow[t]{2}{*}{28} & Norway & 0.995 & 0.998 & 1.017 & 0.986 & 1.003 & 0.984 & 0.986 & 1.055 \\
\hline & Average (total) & & & & & 1.005 & 0.989 & 0.993 & \\
\hline
\end{tabular}

\section{Conclusions}

We developed a new measure of income inequality providing a deeper insight into the distribution of income than aggregated Gini coefficient. The performance income distribution indicator has been demonstrated to favour more Rawlsian distributions. Projections computed from the model provide policy recommendations related to redistributional adjustments in particular income groups. The intertemporal analysis revealed a slight deterioration in income distribution towards a less egalitarian structure. This finding is, on average, confirmed by the increasing value of the Gini coefficient. The results show that a more clear-cut discrimination could be achieved by selecting the more restrictive set of weights. In general, the proposed relative indicator with its merits of providing deeper insights into income distribution among individuals, is meant to supplement and extend statistically based aggregated indicators like the Gini or Theil indices with information applicable for policy making. The restricted multipliers approach presents a promising avenue for examining poverty indicators in a similar fashion.

Acknowledgements Open access funding provided by Vienna University of Economics and Business (WU). We are grateful for helpful comments and suggestions by the two anonymous referees, while stressing that the remaining errors and omissions are entirely the responsibility of the authors.

Funding This research is supported by Grant APVV-15-0765 "Inequality and economic growth" of the Slovak Research and Development Agency.

\section{Compliance with ethical standards}

Conflict of interest The authors declared that they have no conflict of interest. 
Open Access This article is distributed under the terms of the Creative Commons Attribution 4.0 International License (http://creativecommons.org/licenses/by/4.0/), which permits unrestricted use, distribution, and reproduction in any medium, provided you give appropriate credit to the original author(s) and the source, provide a link to the Creative Commons license, and indicate if changes were made.

\section{Appendix A}

See Tables 5, 6, 7 and 8 .

Table 5 Income shares and the Gini coefficients data. Source: Eurostat

\begin{tabular}{|c|c|c|c|c|c|c|c|c|c|c|c|c|}
\hline & \multicolumn{6}{|l|}{2007} & \multicolumn{6}{|l|}{2016} \\
\hline & Q1 & $\mathrm{Q} 2$ & Q3 & Q4 & Q5 & Gini & Q1 & Q2 & Q3 & Q4 & Q5 & Gini \\
\hline Belgium & 9.1 & 14.1 & 18.4 & 23.1 & 35.3 & 26.3 & 9.1 & 13.9 & 18.4 & 23.5 & 35.1 & 26.3 \\
\hline Bulgaria & 5.9 & 12.3 & 17.2 & 23.2 & 41.4 & 35.3 & 5.6 & 11.4 & 16.2 & 22.6 & 44.2 & 38.3 \\
\hline Czech Republic & 10.1 & 14.5 & 17.7 & 22.1 & 35.6 & 25.3 & 10.1 & 14.6 & 17.9 & 22 & 35.4 & 25.1 \\
\hline Denmark & 9.2 & 15 & 18.6 & 22.6 & 34.6 & 25.2 & 9 & 14.2 & 17.9 & 22.2 & 36.7 & 27.7 \\
\hline Germany & 7.8 & 13.7 & 17.5 & 22.5 & 38.5 & 30.4 & 8.2 & 13.5 & 17.7 & 22.8 & 37.8 & 29.5 \\
\hline Estonia & 7.4 & 12.3 & 16.8 & 22.5 & 41 & 33.4 & 7.1 & 12.1 & 17.1 & 23.9 & 39.8 & 32.7 \\
\hline Ireland & 8.2 & 12.6 & 16.8 & 23.1 & 39.3 & 31.3 & 8.6 & 13.1 & 17.6 & 22.9 & 37.8 & 29.5 \\
\hline Greece & 6.9 & 12.2 & 16.8 & 22.8 & 41.3 & 34.3 & 6.2 & 12.5 & 17.3 & 23.5 & 40.5 & 34.3 \\
\hline Spain & 7.1 & 12.8 & 17.6 & 23.6 & 38.9 & 31.9 & 6.2 & 12.2 & 17.3 & 23.7 & 40.6 & 34.5 \\
\hline France & 9.3 & 14.2 & 17.9 & 22.5 & 36.1 & 26.6 & 8.9 & 13.7 & 17.2 & 21.6 & 38.6 & 29.3 \\
\hline Italy & 7.3 & 12.8 & 17.5 & 23.1 & 39.3 & 32.0 & 6.3 & 12.8 & 17.9 & 23.5 & 39.5 & 33.1 \\
\hline Cyprus & 8.7 & 13.4 & 17.3 & 22 & 38.6 & 29.8 & 8.3 & 12.4 & 16.7 & 22.2 & 40.4 & 32.1 \\
\hline Latvia & 6.6 & 11.7 & 16.5 & 23.4 & 41.8 & 35.4 & 6.6 & 12 & 16.9 & 23.3 & 41.2 & 34.5 \\
\hline Lithuania & 7 & 12.4 & 16.7 & 22.7 & 41.2 & 33.8 & 6.1 & 11.4 & 16.2 & 22.9 & 43.4 & 37.0 \\
\hline Luxembourg & 9.1 & 13.9 & 17.6 & 22.6 & 36.8 & 27.4 & 7.8 & 13.1 & 17.3 & 22.8 & 39 & 31.0 \\
\hline Hungary & 9.6 & 14.6 & 18 & 22.5 & 35.3 & 25.6 & 8.6 & 13.9 & 17.8 & 22.9 & 36.8 & 28.2 \\
\hline Malta & 9.1 & 14.1 & 18.3 & 23.1 & 35.4 & 26.3 & 8.9 & 13.3 & 17.7 & 22.8 & 37.3 & 28.5 \\
\hline Netherlands & 9.3 & 14.1 & 17.6 & 22 & 37 & 27.6 & 9.2 & 14.1 & 17.9 & 22.6 & 36.2 & 26.9 \\
\hline Austria & 9.5 & 14.4 & 17.9 & 22.3 & 35.9 & 26.2 & 8.8 & 14.2 & 18.2 & 22.8 & 36 & 27.2 \\
\hline Poland & 7.6 & 12.8 & 17 & 22.5 & 40.1 & 32.2 & 7.9 & 13.4 & 17.7 & 23.1 & 37.9 & 29.8 \\
\hline Portugal & 6.9 & 11.5 & 15.4 & 21.8 & 44.4 & 36.8 & 7 & 12.4 & 16.7 & 22.6 & 41.3 & 33.9 \\
\hline Romania & 5.4 & 11.1 & 16.5 & 22.9 & 44.1 & 38.3 & 5.5 & 12 & 17.9 & 24.6 & 40 & 34.7 \\
\hline Slovenia & 10.1 & 15.2 & 18.5 & 22.8 & 33.4 & 23.2 & 9.5 & 14.9 & 18.7 & 22.9 & 34 & 24.4 \\
\hline Slovakia & 10 & 14.9 & 18.2 & 22.3 & 34.6 & 24.5 & 9.3 & 15.2 & 18.8 & 23 & 33.7 & 24.3 \\
\hline Finland & 9.7 & 14.2 & 18 & 22.4 & 35.7 & 26.2 & 9.9 & 14.3 & 18 & 22.4 & 35.4 & 25.4 \\
\hline Sweden & 10 & 15.2 & 18.7 & 22.7 & 33.4 & 23.4 & 8.5 & 14.1 & 18.4 & 23.2 & 35.8 & 27.6 \\
\hline United Kingdom & 7.6 & 12.6 & 17 & 22.5 & 40.3 & 32.6 & 7.7 & 13 & 17.2 & 22.9 & 39.2 & 31.5 \\
\hline Norway & 9.4 & 15.6 & 19 & 22.7 & 33.3 & 23.7 & 9.4 & 15.1 & 18.5 & 22.4 & 34.6 & 25.0 \\
\hline Switzerland & 8.3 & 13.3 & 17.3 & 22.3 & 38.8 & 30.4 & 8.6 & 13.5 & 17.4 & 22.4 & 38.1 & 29.4 \\
\hline
\end{tabular}


Table 6 Projections of the income shares for $l=0.9$ (2016)

\begin{tabular}{|c|c|c|c|c|c|c|}
\hline & \multirow[t]{2}{*}{ Score } & \multicolumn{5}{|c|}{ Adjustment } \\
\hline & & Q1 & Q2 & Q3 & Q4 & Q5 \\
\hline Belgium & 0.997 & 0.20 & 1.30 & 0.40 & -0.50 & -1.40 \\
\hline Bulgaria & 0.984 & 3.70 & 3.80 & 2.60 & 0.40 & -10.50 \\
\hline Czech Republic & 1 & 0 & 0 & 0 & 0 & 0 \\
\hline Denmark & 0.997 & 0.30 & 1.00 & 0.90 & 0.80 & -3.00 \\
\hline Germany & 0.994 & 1.10 & 1.70 & 1.10 & 0.20 & -4.10 \\
\hline Estonia & 0.989 & 2.20 & 3.10 & 1.70 & -0.90 & -6.10 \\
\hline Ireland & 0.994 & 0.70 & 2.10 & 1.20 & 0.10 & -4.10 \\
\hline Greece & 0.988 & 3.10 & 2.70 & 1.50 & -0.50 & -6.80 \\
\hline Spain & 0.988 & 3.10 & 3.00 & 1.50 & -0.70 & -6.90 \\
\hline France & 0.995 & 0.40 & 1.50 & 1.60 & 1.40 & -4.90 \\
\hline Italy & 0.989 & 3.00 & 2.40 & 0.90 & -0.50 & -5.80 \\
\hline Cyprus & 0.991 & 1.00 & 2.80 & 2.10 & 0.80 & -6.70 \\
\hline Latvia & 0.988 & 2.70 & 3.20 & 1.90 & -0.30 & -7.50 \\
\hline Lithuania & 0.985 & 3.20 & 3.80 & 2.60 & 0.10 & -9.70 \\
\hline Luxembourg & 0.992 & 1.50 & 2.10 & 1.50 & 0.20 & -5.30 \\
\hline Hungary & 0.995 & 0.70 & 1.30 & 1.00 & 0.10 & -3.10 \\
\hline Malta & 0.995 & 0.40 & 1.90 & 1.10 & 0.20 & -3.60 \\
\hline Netherlands & 0.997 & 0.10 & 1.10 & 0.90 & 0.40 & -2.50 \\
\hline Austria & 0.997 & 0.50 & 1.00 & 0.60 & 0.20 & -2.30 \\
\hline Poland & 0.993 & 1.40 & 1.80 & 1.10 & -0.10 & -4.20 \\
\hline Portugal & 0.989 & 2.30 & 2.80 & 2.10 & 0.40 & -7.60 \\
\hline Romania & 0.987 & 3.80 & 3.20 & 0.90 & -1.60 & -6.30 \\
\hline Slovenia & 1 & 0 & 0 & 0 & 0 & 0 \\
\hline Slovakia & 1 & 0 & 0 & 0 & 0 & 0 \\
\hline Finland & 0.999 & 0.01 & 0.44 & 0.12 & -0.16 & -0.41 \\
\hline Sweden & 0.996 & 0.80 & 1.10 & 0.40 & -0.20 & -2.10 \\
\hline United King & 0.992 & 1.60 & 2.20 & 1.60 & 0.10 & -5.50 \\
\hline Norway & 1.000 & 0.00 & 0.02 & 0.18 & 0.47 & -0.68 \\
\hline Switzerland & 0.994 & 0.70 & 1.70 & 1.40 & 0.60 & -4.40 \\
\hline
\end{tabular}


Table 7 The Malmquist index components $(l=0.9)$ and the Gini index $(2007,2016)$. Source: Authors' calculations

\begin{tabular}{|c|c|c|c|c|c|c|c|c|c|c|}
\hline & & $\mathrm{d} 11$ & $\mathrm{~d} 22$ & $\mathrm{~d} 21$ & $\mathrm{~d} 12$ & $\mathrm{C}$ & $\mathrm{F}$ & M & G07 & G16 \\
\hline 1 & Belgium & 0.992 & 0.995 & 0.995 & 0.992 & 1.003 & 0.997 & 1.000 & 26.3 & 26.3 \\
\hline 2 & Bulgaria & 0.970 & 0.966 & 0.973 & 0.963 & 0.996 & 0.997 & 0.993 & 35.3 & 38.3 \\
\hline 3 & Czech Republic & 0.999 & 1.000 & 1.000 & 1.000 & 1.000 & 1.000 & 1.000 & 25.3 & 25.1 \\
\hline 4 & Denmark & 0.995 & 0.993 & 0.998 & 0.990 & 0.998 & 0.997 & 0.995 & 25.2 & 27.7 \\
\hline 5 & Germany & 0.983 & 0.987 & 0.985 & 0.985 & 1.005 & 0.997 & 1.002 & 30.4 & 29.5 \\
\hline 6 & Estonia & 0.975 & 0.978 & 0.978 & 0.975 & 1.003 & 0.997 & 1.000 & 33.4 & 32.7 \\
\hline 7 & Ireland & 0.980 & 0.988 & 0.983 & 0.985 & 1.008 & 0.997 & 1.005 & 31.3 & 29.5 \\
\hline 8 & Greece & 0.973 & 0.975 & 0.976 & 0.972 & 1.002 & 0.997 & 0.999 & 34.3 & 34.3 \\
\hline 9 & Spain & 0.978 & 0.974 & 0.981 & 0.972 & 0.996 & 0.997 & 0.993 & 31.9 & 34.5 \\
\hline 10 & France & 0.992 & 0.989 & 0.995 & 0.986 & 0.997 & 0.997 & 0.994 & 26.6 & 29.3 \\
\hline 11 & Italy & 0.978 & 0.978 & 0.981 & 0.975 & 0.999 & 0.997 & 0.997 & 32.0 & 33.1 \\
\hline 12 & Cyprus & 0.985 & 0.982 & 0.988 & 0.979 & 0.997 & 0.997 & 0.994 & 29.8 & 32.1 \\
\hline 13 & Latvia & 0.970 & 0.974 & 0.973 & 0.972 & 1.004 & 0.997 & 1.002 & 35.4 & 34.5 \\
\hline 14 & Lithuania & 0.974 & 0.968 & 0.976 & 0.966 & 0.995 & 0.997 & 0.992 & 33.8 & 37.0 \\
\hline 15 & Luxembourg & 0.989 & 0.983 & 0.992 & 0.981 & 0.994 & 0.997 & 0.991 & 27.4 & 31.0 \\
\hline 16 & Hungary & 0.995 & 0.991 & 0.998 & 0.988 & 0.996 & 0.997 & 0.993 & 25.6 & 28.2 \\
\hline 17 & Malta & 0.992 & 0.990 & 0.995 & 0.987 & 0.998 & 0.997 & 0.995 & 26.3 & 28.5 \\
\hline 18 & Netherlands & 0.990 & 0.994 & 0.993 & 0.991 & 1.004 & 0.997 & 1.001 & 27.6 & 26.9 \\
\hline 19 & Austria & 0.993 & 0.993 & 0.996 & 0.990 & 1.000 & 0.997 & 0.997 & 26.2 & 27.2 \\
\hline 20 & Poland & 0.978 & 0.986 & 0.981 & 0.983 & 1.008 & 0.997 & 1.005 & 32.2 & 29.8 \\
\hline 21 & Portugal & 0.967 & 0.976 & 0.970 & 0.974 & 1.010 & 0.997 & 1.007 & 36.8 & 33.9 \\
\hline 22 & Romania & 0.962 & 0.973 & 0.965 & 0.970 & 1.011 & 0.997 & 1.008 & 38.3 & 34.7 \\
\hline 23 & Slovenia & 1 & 1 & 1.025 & 0.997 & 1.000 & 0.986 & 0.986 & 23.2 & 24.4 \\
\hline 24 & Slovakia & 0.998 & 1 & 1.009 & 0.997 & 1.002 & 0.993 & 0.995 & 24.5 & 24.3 \\
\hline 25 & Finland & 0.994 & 0.998 & 0.997 & 0.995 & 1.005 & 0.997 & 1.001 & 26.2 & 25.4 \\
\hline 26 & Sweden & 1 & 0.992 & 1.024 & 0.990 & 0.992 & 0.987 & 0.979 & 23.4 & 27.6 \\
\hline 27 & United Kingdom & 0.977 & 0.983 & 0.980 & 0.980 & 1.005 & 0.997 & 1.003 & 32.6 & 31.5 \\
\hline 28 & Norway & 1 & 0.999 & 1.018 & 0.996 & 0.999 & 0.990 & 0.989 & 23.7 & 25.0 \\
\hline \multirow[t]{2}{*}{29} & Switzerland & 0.983 & 0.988 & 0.986 & 0.985 & 1.005 & 0.997 & 1.002 & 30.4 & 29.4 \\
\hline & Average & & & & & 1.001 & 0.996 & 0.997 & & \\
\hline
\end{tabular}


Table 8 Malmquist index components $(l=0.7)$ and the Gini index $(2007,2016)$. Source: Authors' calculations

\begin{tabular}{|c|c|c|c|c|c|c|c|c|c|c|}
\hline & & $\mathrm{d} 11$ & $\mathrm{~d} 22$ & $\mathrm{~d} 21$ & $\mathrm{~d} 12$ & $\mathrm{C}$ & $\mathrm{F}$ & $\mathrm{M}$ & G07 & G16 \\
\hline 1 & Belgium & 0.972 & 0.982 & 0.983 & 0.971 & 1.010 & 0.989 & 0.999 & 26.3 & 26.3 \\
\hline 2 & Bulgaria & 0.895 & 0.884 & 0.905 & 0.874 & 0.988 & 0.989 & 0.977 & 35.3 & 38.3 \\
\hline 3 & Czech Republic & 0.999 & 1 & 1.000 & 0.999 & 1.001 & 0.999 & 1.000 & 25.3 & 25.1 \\
\hline 4 & Denmark & 0.983 & 0.978 & 0.994 & 0.967 & 0.995 & 0.989 & 0.984 & 25.2 & 27.7 \\
\hline 5 & Germany & 0.940 & 0.958 & 0.951 & 0.947 & 1.018 & 0.989 & 1.007 & 30.4 & 29.5 \\
\hline 6 & Estonia & 0.916 & 0.924 & 0.926 & 0.914 & 1.009 & 0.989 & 0.998 & 33.4 & 32.7 \\
\hline 7 & Ireland & 0.934 & 0.960 & 0.944 & 0.949 & 1.028 & 0.989 & 1.017 & 31.3 & 29.5 \\
\hline 8 & Greece & 0.907 & 0.913 & 0.917 & 0.903 & 1.006 & 0.989 & 0.995 & 34.3 & 34.3 \\
\hline 9 & Spain & 0.923 & 0.910 & 0.933 & 0.900 & 0.987 & 0.989 & 0.976 & 31.9 & 34.5 \\
\hline 10 & France & 0.973 & 0.966 & 0.984 & 0.955 & 0.993 & 0.989 & 0.982 & 26.6 & 29.3 \\
\hline 11 & Italy & 0.924 & 0.921 & 0.935 & 0.911 & 0.996 & 0.989 & 0.985 & 32.0 & 33.1 \\
\hline 12 & Cyprus & 0.950 & 0.941 & 0.961 & 0.931 & 0.990 & 0.989 & 0.979 & 29.8 & 32.1 \\
\hline 13 & Latvia & 0.897 & 0.912 & 0.907 & 0.902 & 1.017 & 0.989 & 1.006 & 35.4 & 34.5 \\
\hline 14 & Lithuania & 0.910 & 0.893 & 0.920 & 0.883 & 0.981 & 0.989 & 0.970 & 33.8 & 37.0 \\
\hline 15 & Luxembourg & 0.965 & 0.944 & 0.976 & 0.934 & 0.979 & 0.989 & 0.968 & 27.4 & 31.0 \\
\hline 16 & Hungary & 0.982 & 0.969 & 0.993 & 0.958 & 0.987 & 0.989 & 0.976 & 25.6 & 28.2 \\
\hline 17 & Malta & 0.972 & 0.967 & 0.983 & 0.956 & 0.995 & 0.989 & 0.984 & 26.3 & 28.5 \\
\hline 18 & Netherlands & 0.969 & 0.981 & 0.980 & 0.970 & 1.013 & 0.989 & 1.001 & 27.6 & 26.9 \\
\hline 19 & Austria & 0.978 & 0.978 & 0.989 & 0.967 & 1.000 & 0.989 & 0.989 & 26.2 & 27.2 \\
\hline 20 & Poland & 0.925 & 0.952 & 0.936 & 0.942 & 1.029 & 0.989 & 1.018 & 32.2 & 29.8 \\
\hline 21 & Portugal & 0.890 & 0.920 & 0.900 & 0.910 & 1.034 & 0.989 & 1.022 & 36.8 & 33.9 \\
\hline 22 & Romania & 0.870 & 0.902 & 0.880 & 0.892 & 1.037 & 0.989 & 1.026 & 38.3 & 34.7 \\
\hline 23 & Slovenia & 1 & 1 & 1.024 & 0.988 & 1.000 & 0.982 & 0.982 & 23.2 & 24.4 \\
\hline 24 & Slovakia & 0.993 & 1 & 1.008 & 0.989 & 1.008 & 0.986 & 0.994 & 24.5 & 24.3 \\
\hline 25 & Finland & 0.980 & 0.995 & 0.991 & 0.984 & 1.016 & 0.989 & 1.004 & 26.2 & 25.4 \\
\hline 26 & Sweden & 0.999 & 0.973 & 1.024 & 0.963 & 0.974 & 0.983 & 0.957 & 23.4 & 27.6 \\
\hline 27 & United Kingdom & 0.923 & 0.941 & 0.934 & 0.931 & 1.020 & 0.989 & 1.008 & 32.6 & 31.5 \\
\hline 28 & Norway & 0.995 & 0.998 & 1.017 & 0.986 & 1.003 & 0.984 & 0.986 & 23.7 & 25.0 \\
\hline \multirow[t]{2}{*}{29} & Switzerland & 0.943 & 0.962 & 0.954 & 0.951 & 1.020 & 0.989 & 1.008 & 30.4 & 29.4 \\
\hline & Average & & & & & 1.005 & 0.989 & 0.993 & & \\
\hline
\end{tabular}

\section{Appendix B: Sum of the projected income shares}

Given the optimal solutions for $\lambda$, projections for $s$ quintiles and $n$ DMUs are given by 


$$
\hat{\mathbf{y}}_{0}=\left(\begin{array}{c}
\hat{y}_{10} \\
\hat{y}_{20} \\
\vdots \\
\hat{y}_{s 0}
\end{array}\right)=\mathbf{Y} \lambda^{*}=\left(\begin{array}{c}
\sum_{j=1}^{n} y_{1 j} \lambda_{j}^{*} \\
\sum_{j=1}^{n} y_{2 j} \lambda_{j}^{*} \\
\vdots \\
\sum_{j=1}^{n} y_{s j} \lambda_{j}^{*}
\end{array}\right) \text {, }
$$

and the sum of the projected shares is $\sum_{r=1}^{s} \sum_{j=1}^{n} y_{r j} \lambda_{j}^{*}=\sum_{j=1}^{n} \sum_{r=1}^{s} y_{r j} \lambda_{j}^{*}=\sum_{j=1}^{n}\left(\lambda_{j}^{*} \sum_{r=1}^{s} y_{r j}\right)=\sum_{j=1}^{n} \lambda_{j}^{*}$.

Since the single input is fixed to 1 and projected onto itself, for the sum of lambdas we have

$$
\hat{x}_{0}=\sum_{j=1}^{n} x_{j} \lambda_{j}^{*}=\sum_{j=1}^{n} \lambda_{j}^{*}=1 .
$$

Thus the adjusted income shares generated by the model add up to unity.

\section{References}

Atkinson AB (2015) Inequality. Harvard University Press, Cambridge

Atkinson AB, Piketty T, Saez E (2011) Top incomes in the long-run of history. J Econ Lit 49(1):3-71

Caves D, Christensen L, Diewert E (1982) The economic theory of index numbers and the measurement of input, output, and productivity. Econometrics 50:1393-1414

Charnes A, Cooper W, Rhodes E (1978) Measuring the efficiency of decision making units. Eur J Oper Res 2:429-444

Cooper W, Seiford LM, Tone K (2007) Data envelopment analysis. A comprehensive text with models, applications, references and DEA-solver software, 2nd edn. Springer, New York

Färe R, Grosskopf S (1992) Malmquist productivity indexes and fisher ideal indexes. Econ J 102(410):158-160

Färe R, Grosskopf S, Norris M, Zhang Z (1994) Productivity growth, technical progress, and efficiency changes in industrialized countries. Am Econ Rev 84(1):66-83

Feldstein M (2005) Rethinking social insurance. Am Econ Rev 95(1):1-24

Jones CI, Klenow PJ (2016) Beyond GDP? Welfare across countries and time. Am Econ Rev 106(9):2426-2457

Lábaj M, Luptáčik M, Nežinský E (2014) Data envelopment analysis for measuring economic growth in terms of welfare beyond GDP. Empirica 41(3):407-424. https://doi.org/10.1007/s10663-014-9262-2

Nicola PC (2013) Efficiency and equity in welfare economics. In: Lecture notes in economics and mathematical systems, vol 661. Springer, Berlin. https://doi.org/10.1007/978-3-642-30071-4

Prasada Rao DS, Coelli TJ (1998) A cross country analysis of GDP growth catch-up and convergence in productivity and inequality. In: CEPA working papers, 5/98, Australia

Prasada Rao DS, Coelli TJ (2002) Economic performance of selected asian countries in an international perspective: economic growth, productivity and inequality. In: Fu TT, Huang CJ, Lovell CAK (eds) Economic efficiency and productivity growth in the Asia-Pacific Region. Edward Elgar, Cheltenham, pp 100-137

Rawls J (1971) A theory of justice. Harvard University Press, Cambridge

Sen A (2000) Social justice and the distribution of income. In: Atkinson A, Bourguignon F (eds) Handbook of income distribution, vol 1. Elsevier, Amsterdam 
Stiglitz JE, Sen AK, Fitoussi JP (2009) Report by the commission on the measurement of economic performance and social progress. https://ec.europa.eu/eurostat/documents/118025/118123/Fitou ssi+Commission+report

Thompson RG, Singleton FD, Thrall RM, Smith BA (1986) Comparative site evaluations for locating a high-energy physics lab in Texas. Interfaces 16(6):35-49. https://doi.org/10.1287/inte.16.6.35

Publisher's Note Springer Nature remains neutral with regard to jurisdictional claims in published maps and institutional affiliations. 